Revue d'histoire de l'enfance « irrégulière »

Le Temps de l'histoire

19 | 2017

Abandon d'enfants et parents abandonneurs, $X I X X^{e}-\left.X X\right|^{e}$ siècles

\title{
Le Centre international de l'enfance (1949-1997)
}

Jean-Jacques Yvorel

\section{OpenEdition}

Journals

Édition électronique

URL : https://journals.openedition.org/rhei/4102

DOI : $10.4000 /$ rhei.4102

ISSN : $1777-540 \mathrm{X}$

Éditeur

Presses universitaires de Rennes

Édition imprimée

Date de publication : 22 novembre 2017

Pagination : 221-222

ISBN : 978-2-7535-6467-7

ISSN : 1287-2431

Référence électronique

Jean-Jacques Yvorel, « Le Centre international de l'enfance (1949-1997) », Revue d'histoire de l'enfance « irrégulière » [En ligne], 19 | 2017, mis en ligne le 22 novembre 2017, consulté le 09 septembre 2021.

URL : http://journals.openedition.org/rhei/4102 ; DOI : https://doi.org/10.4000/rhei.4102 
situation sociale et familiale de danger. Ce mouvement a donné lieu dans les années 1990, à diverses réflexions juridiques, éducatives et même psychiatriques, qui justifient progressivement l'usage éducatif de la norme pénale dans « une économie morale fondée sur l'impératif de la responsabilisation par rapport à l'acte ». Le recentrage de l'activité pédagogique sur l'acte accroît, dans l'action éducative, le poids de la responsabilisation du jeune qui fait de la contrainte un élément central du traitement du jeune délinquant. Ceci s'inscrit, pour N. Sallée, dans une dynamique plus générale depuis les années 1990, marquée par « un transfert des risques sociaux vers l'individu, un outil privilégié participant au contrôle et à la responsabilisation des populations les plus marginalisées ". Le rôle de l'éducateur n'en est que plus ambigu, jusqu'à remettre en cause son autonomie professionnelle en développant un modèle éducatif où la "responsabilisation renoue avec les vieilles utopies disciplinaires». L'éducateur que je fus et la connaissance que j'ai de cette histoire me font pleinement adhérer aux analyses de N. Sallée.

Jacques Bourquin

\section{Le Centre international de l'enfance (1949-1997). \\ Des archives à l'histoire \\ Yves Denéchère et Patrice Marcilloux (dir.) \\ 2016}

Presses universitaires de Rennes, Rennes, 2016, 202 p.,

ISBN : 9782753548688.

Cet ouvrage est issu d'un colloque qui s'est tenu à Angers en 2014. Pourquoi à Angers alors que le Centre international de l'enfance avait son siège à Longchamp? Parce que l'université du Maine-et-Loire a participé au sauvetage des archives et du fonds documentaire de cette institution qui semblaient promis au pilon. Le livre rassemble des textes de natures très différentes comme tous les actes de manifestations scientifiques où se croisent les historiens et les acteurs/témoins: les articles d'historiens et les présentations d'archives voisinent avec des témoignages.

Il s'ouvre, après une introduction qui explicite la démarche et les objectifs de cette rencontre, sur une biographie quelque peu hagiographique et peu problématisée du fondateur du Centre international de l'enfance, Robert Debré (Sedan 1882-Paris 1978), par son petit-fils. 
La journée d'étude était également destinée à valoriser les archives et le fonds documentaire du Centre international de l'enfance dont l'université d'Angers est dépositaire, ainsi qu'à susciter des recherches futures. Dans une première partie, Matériaux, Damien Hamard et Maxime Szczepanski font une présentation raisonnée de fonds archivistiques et documentaires conservés à Angers. Quant à Patrice Marcilloux, il nous propose une étude originale sur La création du Centre international de l'enfance constituée uniquement par des pièces d'archives qui sont simplement mais savamment annotées. Cette première partie se clôt par un entretien (réalisé par David Niget et Angélique Martin) avec le professeur Michel Manciaux, grand promoteur de la pédiatrie préventive et sociale, qui dirigea le Centre de 1974 à 1983.

La seconde partie, consacrée à la Formation et recherche au Centre international de l'enfance, s'ouvre sur un article de Pascale Quincy-Lefebvre sur Le cours international de pédiatrie sociale, avant de recueillir les témoignages sur les aspects particuliers de l'activé du Centre, comme celui du docteur Michel Péchevis sur les méthodes pédagogiques ou celui de l'anthropologue Jon M. Cook sur la pluridisciplinarité en matière de recherches.

Yves Denéchère introduit la troisième partie centrée sur L'Afrique: terrain privilégié du Centre international de l'enfance, avec un article sur L'action du Centre international de l'enfance dans l'espace coloniale français en Afrique entre 1949 et 1960. Gaëtan Thomas, spécialiste de l'histoire des sciences, se penche lui sur la station pilote de vaccination que le Centre avait initié au Cameroun dans les années 1970. Enfin, le docteur Michel Chauliac témoigne de l'esprit qui animait l'équipe rédactionnelle de l'une des revues publiées par le Centre, L'enfant en milieu tropical.

$\mathrm{Au}$ Centre international de l'enfance se croisent l'histoire des sciences et de la médecine, l'histoire de la colonisation et de la décolonisation, l'histoire des organisations internationales et du rôle de la France dans ces diverses histoires, l'histoire des réseaux associatifs où se côtoient hommes politiques, intellectuels influents et grands commis de l'État. Il y a là une multitude de chantiers Centre international de l'enfance que les directeurs de la publication nous invitent, dans une solide conclusion, à ouvrir.

Jean-Jacques Yvorel 